by the JCAHO or other institutions judged acceptable by the Board. Diplomates must also submit letter(s) of reference documenting their level of clinical activity and stature within the surgical community from the VP of Medical Affairs and one other responsible member on staff at their principal hospital. In addition, a valid ABTS certificate is an absolute requirement for entrance into the MOC process. If your certificate has expired, the only pathway for renewal of a certificate is to take and pass the Part I (written) and the Part II (oral) certifying examinations.

The CME requirements are 150 Category I credits over a five-year period. At least half of these CME hours need to be in the broad area of thoracic surgery. Category II credits are not accepted. Interested individuals should refer to the Board's Web site (www.abts.org) for a complete description of acceptable CME credits.

This year, the Board has changed the format of the MOC exam. Instead of taking the MOC exam at a testing center, the Board wants Diplomates to be aware that they will be taking the exam on their personal or office computer. The Diplomate will need to have a Web camera that will work in conjunction with the software for security purposes. The Board is transitioning to using SESATS as the mastery learning tool. Each time a Diplomate logs on to the site, he or she will be asked to hold his or her license (with a picture) to secure verification. The Diplomate will also be asked to provide a scan of the immediate area for security purposes.

The online MOC exam must be completed during the time period of September 1, 2015, to October 31, 2015. Diplomates will be allowed to enter the online program 10 times for a total of 15 hours. If the exam is not completed within those parameters, it will be considered incomplete. The fee for sitting for the MOC secure exam is $\$ 125.00$. This fee covers the expenses associated with software needed to ensure the online exam is secure. Questions on the MOC exam will be modular, based on your specialty, and presented in a self-assessment format.

The American Board of Thoracic Surgery has voted to replace the requirement for mandatory database participation with Performance Improvement. The Board is requiring clinically active Diplomates to participate in a Practice Quality Improvement (PQI) project by January 2016. For those clinically active Diplomates who do not participate in a Board-approved database/ registry, the Board will continue to require participation in the Professional Portfolio until the PQI process starts.

Diplomates may apply for MOC in the year their certificate expires or, if they wish to do so, they may apply up to two years before it expires. However, the new certificate will be dated 10 years from the date of expiration of their original certificate or most recent MOC certificate. In other words, going through the MOC process early does not alter the 10-year validation. Diplomates certified prior to 1976 (the year that time-limited certificates were initiated) are also required to participate in MOC if they wish to maintain valid certificates.

Information outlining the rules, requirements, and application deadline for the 10-year Milestone of MOC in thoracic surgery is available on the Board's Web site at www. abts.org. For additional information, please contact the American Board of Thoracic Surgery, 633 N Saint Clair St, Ste 2320, Chicago, IL 60611; telephone (312) 2025900; fax (312) 202-5960; E-mail: sesats@abts.org.

\section{Thoracic Surgery Foundation for Research and Education}

\section{TSFRE 2016 Awards Program}

Thoracic Surgery Foundation for Research and Education (TSFRE) is offering several 2016 awards to qualified applicants. Please visit the TSFRE Awards Page or www.tsfre.org for detailed information and to access grant applications. Questions about eligibility can be directed to Priscilla Kennedy, TSFRE Executive Director, by E-mail at pkennedy@tsfre.org. The application deadline for the following awards is October 15, 2015.

\section{TSFRE Research Grant}

Provides operational support for original research efforts by cardiothoracic surgeons who have completed their formal training, and who are seeking initial support and recognition for their research program. Awards of up to $\$ 40,000$ per year for up to two years are granted to support the work of an early-career cardiothoracic surgeon (within five years of first faculty appointment at time of application deadline).

\section{Acelity Wound Care Research Grant}

TSFRE, through the generosity and philanthropy of Acelity, is offering support of up to $\$ 25,000$ to support the research efforts by cardiothoracic surgeons who have completed their formal training, and who are seeking support and recognition for their research program related to wound care management. This is the first year this award is being offered, and is focused on wound healing, care, and infection improvement.

\section{TSFRE/Edwards Lifesciences Every Heartbeat Matters} Award

TSFRE, through the generosity and philanthropy of the Edwards Lifesciences Foundation via its Every Heartbeat 
Matters Campaign, is offering support of up to $\$ 37,500$ for qualified surgeons who conduct charity work in underserved regions. This award is designed to provide support for programs that educate, screen, and/or treat underserved populations to reduce the global burden of heart valve disease, or to support other programs that advance health care and address underserved populations.

\section{Nina Starr Braunwald Research Grant \\ Nina Starr Braunwald, MD, was the first woman to both be certified by the ABTS and conduct open heart sur- gery. This award in her name provides operational sup- port of original research efforts by women cardiac surgeons who have completed their formal training, and who are seeking initial support and recognition for their research program. Since inception, recipients of this award have gone on to become established leaders within our field and it is one of our specialty's most prestigious research grants. Awards of up to $\$ 40,000$ per year for up to two years are made each year to sup- port the work of an early career woman cardiac surgeon (within five years of first faculty appointment at the time of application deadline).}

\section{Southern Thoracic Surgical Association (STSA) Research Grant}

TSFRE, through the generosity and philanthropy of STSA, is offering this award that will provide operational support of original research efforts by cardiothoracic surgeons who have completed their formal training and who are seeking initial support and recognition for their research program. Awards of up to $\$ 25,000$ for one year will be granted to support the work of an early-career cardiothoracic surgeon (within seven years of first faculty appointment at the time of application deadline). STSA membership is not required; however, applicants must meet STSA membership eligibility requirements.

\section{Carolyn E. Reed Traveling Fellowship}

Carolyn E. Reed, MD, was a thoracic surgeon, an educator, and a successful researcher, who died early while still in her prime. She served as the first female Chair of the ABTS and was also President of the STSA and STS. This award in her name provides support of $\$ 10,000$ for a clinically established woman thoracic or cardiac surgeon, or woman resident in her last year of cardiothoracic surgery residency, to travel to another in- stitution for the purpose of learning a new skill or technology.

\section{Nina Starr Braunwald Research Fellowship}

Nina Starr Braunwald, MD, was the first woman to both be certified by the ABTS and conduct open heart surgery. This award in her name supports up to $\$ 30,000$ per year for up to two years for a woman resident working in a cardiac surgical clinic or laboratory research program who has not yet completed cardiothoracic surgical training. Recipients of this award have gone on to become established leaders within our field and it is one of our specialty's most prestigious research fellowships.

\section{Research and Education Committee}

Thomas K. Waddell, MD*

Richard Battafarano, MD, PhD

Juan A. Crestanello, MD

James L. Donahue, MD

Pirooz Eghtesady, MD, PhD

Arnar Geirsson, MD

Thomas G. Gleason, MD

Sunjay Kaushal, MD, PhD

Edward H. Kincaid, MD

Paul M. Kirshbom, MD

Daniel Kreisel, MD, PhD

Alexander S. Krupnick, MD

Christine L. Lau, MD

Scott A. LeMaire, MD

Jules Lin, MD

Mark W. Onaitis, MD

Kalpaj R. Parekh, MD

T. Brett Reece, MD

Brendon M. Stiles, MD

Elaine E. Tseng, MD

Dennis A. Wigle, MD, PhD

*2016 Chair

\section{Research Awards Timeline*}

- Grant Applications Available: July 15, 2015

- Application Deadline: October 15, 2015

- Research Committee Meeting: January 23, 2016

- TSFRE Board Meeting: January 24, 2016

- Awards Announcement: February 1, 2016

*Subject to change 